\title{
The Criterion of Particle-Induced Cracking of Filled Polymers
}

\author{
Sergey Bazhenov ${ }^{1} \&$ Galina Goncharuk ${ }^{1}$ \\ ${ }^{1}$ Institute of Chemical Physics, Kosygin Street 4, Moscow, Russia \\ Correspondence: Sergey Bazhenov, Polymer Division, Institute of Chemical Physics, Kosygin Street 4, Moscow \\ 119334, Russia. Tel: 7-495-135-1521. E-mail: Bazhenov_sl@rambler.ru
}

Received: November 14, $2013 \quad$ Accepted: December 9, $2013 \quad$ Online Published: December 19, 2013
$\begin{aligned} & \text { doi:10.5539/jmsr.v3n1p77 } \\ & \text { URL: http://dx.doi.org/10.5539/jmsr.v3n1p77 }\end{aligned}$

\begin{abstract}
Failure of high density polyethylene, low density polyethylene, and polypropylene filled with grinded rubber particles was studied. In tension, particles debond from the matrix and initiate appearance of pores. Small particles lead to formation of elliptical pores. In contrast, large particles initiate appearance of diamond cracks leading to fast failure of filled polymer. In the intermediate case elliptical pore gradually transforms into diamond crack. The diamond crack appears when the elongation of an elliptical pore reaches the critical crack tip opening of the unfilled polymer. The size $D$ of filler particles should be lower than $\left.D_{c}=G_{I c} /\left[\left(\lambda_{d}-1\right) \sigma_{d}\right)\right]$, where $G_{I c}$ is the fracture toughness, $\sigma_{d}-$ the draw stress and $\lambda_{d}$-the natural draw ratio of the matrix in the neck. Ductile or brittle behavior of filled polymer depends on whether the polymer yields uniformly or with necking. If the neck does not appear, filler particles usually do not initiate brittle fracture. In contrast, filled polymers, yielding with necking, often are brittle.
\end{abstract}

Keywords: filled polymer, fracture toughness, particles, crack tip opening, diamond cracks

\section{Introduction}

Permanently growing use of polymers leads to an increase in volume of used polymers. Over the last years the volume of industrial waste has largely increased, creating a problem for today society and future generations. A substantial part of industrial waste is cross-linked rubber that is not thermoplastic and cannot be remolded. One way to recycle cross-linked rubber is to grind the rubber and to use the obtained powder as the filler for thermoplastic polymers (Knunyants et al., 1988; Rajalingam, Sharpe, \& Baker, 1993).

Grinded rubber particles have broad distribution in size, from 10 microns to $1 \mathrm{~mm}$ (Bazhenov, Goncharuk, Knuniantz, Avinkin, \& Serenko, 2002). In contrast to small rubber particles, used to toughen polymers (Bucknall, Cote, \& Partridge, 1986; Wu \& Mai, 1993), large rubber particles are defects initiating failure. For example, brittle fracture of high density polyethylene (HDPE) was observed after introduction of a single large particle into the polymer (Bazhenov, Goncharuk, Knuniantz, Avinkin, \& Serenko, 2002). Brittle fracture of filled polymers is usually accompanied by localized yielding near the fracture surfaces. On this reason the fracture is called quasibrittle ( $\mathrm{Li}$, Silverstein, Hiltner, \& Baer, 1994). The fracture elongation at quasibrittle fracture is roughly 100 -fold lower than that at ductile fracture.

Some polymers, such as superhighmolecularweight polyethylene (SHMWPE) or polyimide under tension yield uniformly. However, usually homogeneous elastic extension is followed by a non-homogeneous yielding; the film thins down in a short region and a neck is formed. Outside of a neck the material is in a state of low stretch, and within the neck stretch is high.

Tensile strength, Young's modulus and toughness of filled polymer composite depend on the size (Topolkaraev et al., 1988; Chao \& Riggleman, 2013), shape, size distribution (Lauke, 2009), the volume fraction of particles, as well as adhesion of the matrix and the particles (Ramsteiner \& Theysohn, 1984; Topolkaraev et al., 1988; Bailly \& Kontopoulou, 2009). The matrix yielding and ductility are also beneficial for tough composite.

The main disadvantage of filled polymers is their tendency to brittle fracture (Bazhenov, Li, Hiltner, \& Baer, 1994; Bazhenov, 1998). However, SHMWPE filled by rigid aluminum particles remains ductile even at the particle content of $60 \%$ by volume (Bazhenov, Grinev, Kudinova, \& Novokshonova, 2010). Under tension, rigid particles debond from the matrix and initiate appearance of pores (Topolkaraev et al., 1988; Tao, Ping, Mei, \& Cheng, 2013). Two types of pores were observed in filled polymers: elliptical pores elongated in tension 
direction and "diamond cracks", which quickly propagate throughout the cross-section of the sample (Li, Silverstein, Hiltner, \& Baer, 1994).

Failure in the presence of defects has been intensively studied for a long time. Clear theoretical foundations of failure have been developed for two opposite cases. The first is fracture of brittle materials for which the energy criterion of the crack initiation was determined (Griffith, 1921). Theory has been developed also for the opposite case of ductile materials where crack growth is caused by large-scale yielding leading to formation of a wedge-shaped crack tip. The angle of the wedge is equal to $90^{\circ}$ for plane strain and to $\sim 70^{\circ}$ for plane stress conditions (McClintock, 1971).

Polymers are usually neither ideally brittle nor ideally ductile, and their properties are intermediate to these two extreme cases. Griffith's theory of brittle fracture is used as a foundation, and efforts are directed on its modification to consider material ductility. Modification of Griffith's theory was successful for materials where yielding is limited to a small volume near the fracture surfaces (Orowan, 1949). In less brittle materials stable "sub-critical" crack growth is observed. In this case, a wedge-shaped crack tip is formed. The crack steadily propagates at a constant wedge angle. Sometimes, a decrease in the wedge angle with the crack length is observed (Bazhenov, 1997).

The goal of the present work was to determine the criterion of appearance of diamond cracks in filled polymers.

\section{Materials Studied}

High density polyethylene (HDPE Lukoten F 3802), a low density polyethylene (LDPE 16803 and LDPE 15803) and polypropylene (PP Lupol A4-70) were used as a matrix. Filler particles were made by grinding of wastes of cross-linked ethylene-propylene-diene rubber. Similar method is described by Adegbite (2013). An SEM image of particles is presented in Figure 1. The particles are different in size and uneven in shape. The size of particles varies from $10 \mu \mathrm{m}$ to $1 \mathrm{~mm}$.

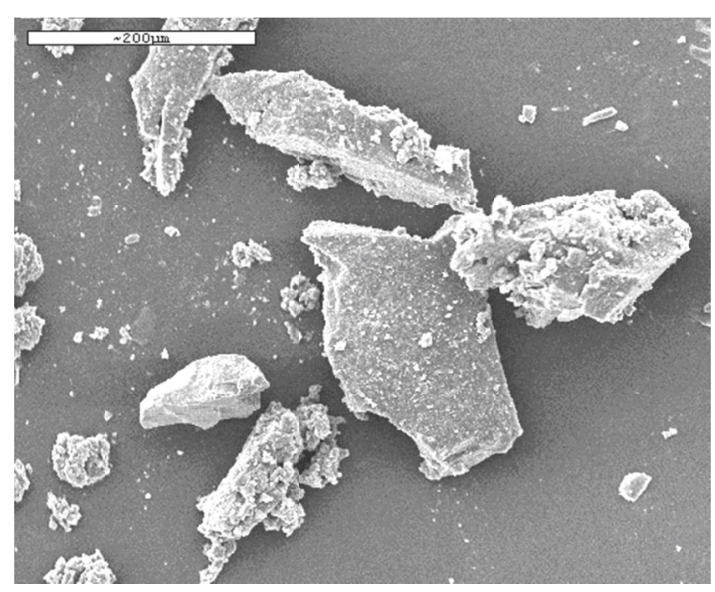

Figure 1. An SEM image of grinded rubber particles

The rubber powder was sieved using a set of 5 calibrated sieves. The sieves separated particles on fractions with particles size $D=50-100,100-200,200-315,315-400,400-600$ and $>600 \mu \mathrm{m}$. The uncieved rubber powder with particle sizes varying from $10 \mu \mathrm{m}$ to $1 \mathrm{~mm}$ was also used.

Thermoplastic polymer and rubber particles were mixed in a single-screw extruder (screw diameter was $32 \mathrm{~mm}$; length to diameter ratio $L / d=12$ ). The filler content was $8 \%$ and $17 \%$ by volume. The plane sheets with size of $100 \times 100 \mathrm{~mm}$ and the thickness of $0.5 \mathrm{~mm}$ were prepared by compression molding of the composite under pressure of $10 \mathrm{MPa}$ for $5 \mathrm{~min}$ at temperature 150, 160, and $190^{\circ} \mathrm{C}$ for LDPE, HDPE and PP respectively. Then the temperature was gradually reduced to $20^{\circ} \mathrm{C}$. Unfilled polymers were pressed similarly.

Dumbbell-shaped samples were cut from the sheets. The length and the width of the samples were 35 and $5 \mathrm{~mm}$ respectively. Samples of unfilled polymers were notched with a razor blade. The notch length was $0.8-1.0 \mathrm{~mm}$.

\section{Methods}

Tensile tests were performed using an Autograph AGS-H testing machine. In addition, minitest machine was used to study crack growth of filled polymers with an optical microscope LOMO Mikmed-2. Crosshead speed 
was $2 \mathrm{~mm} / \mathrm{min}$. During tensile tests, samples were regularly photographed. After fracture, the surface of samples was examined with a Hitachi S-520 scanning electron microscope (SEM). The size of rubber particles in composites was measured with the optical and SEM microscopes.

\section{Results}

\subsection{Filled HDPE}

Figure 2 shows typical engineering stress $\sigma$ - strain $\varepsilon$ curves for HDPE filled with different amount of grinded rubber particles. The stress-strain curve for unfilled HDPE is typical for ductile polymers. After reaching the yield point the stress drops to the draw stress and remained constant while the neck propagates along the specimen. Fracture occurred after the propagation of the neck through the entire sample. Different behavior was observed for filled materials. HDPE filled with $V_{f}=8$ and 17 vol.\% of rubber fractured during formation of the neck. Thus, filler results in a dramatic reduction of the failure strain.

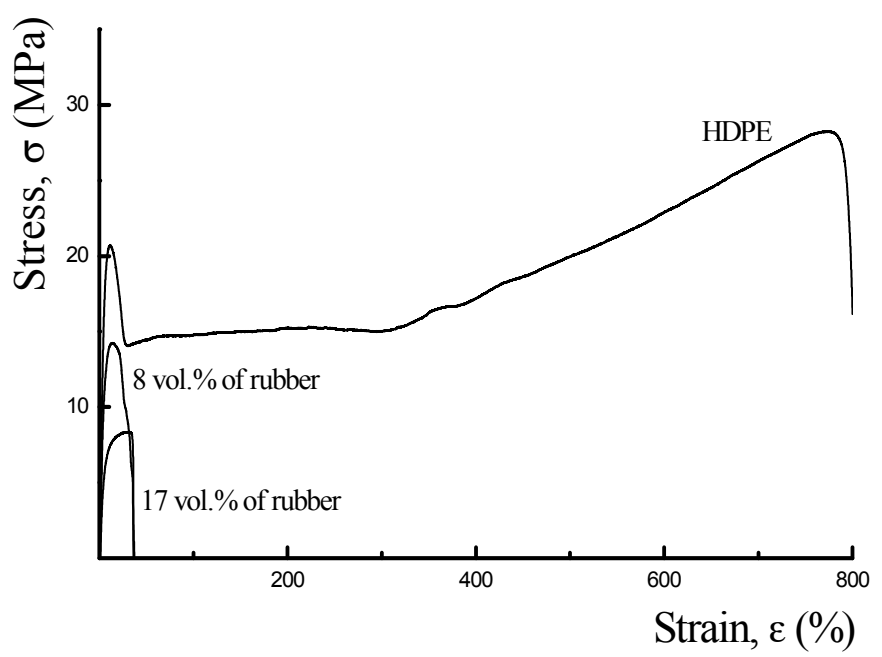

Figure 2. Engineering stress $\sigma$ - strain $\varepsilon$ curves for unfilled HDPE and HDPE filled with $8 \%$ and $17 \%$ by volume of rubber particles

Figure 3 shows SEM images of HDPE filled with 17 vol.\% of rubber particles after tensile fracture. The particles were not sieved and their size varied from 10 to $1000 \mu \mathrm{m}$. The arrow shows the elongation direction. On the Figure 3a the large diamond crack and two small elliptical pores are observed. The diamond crack is elongated in the tension direction and its length is $\approx 1.5 \mathrm{~mm}$. Figure $3 \mathrm{~b}$ represents the enlarged image of the diamond crack. The HDPE is torn in the tip of the diamond crack, and it grows in three directions. As a result, the composite fractures at low strains. The enlarged SEM image of elliptical pores is shown in Figure 3c. The parts of broken and dewetted rubber particles are observed on Figure 3c. In contrast to the diamond cracks, elliptical pores do not initiate failure of the composite.

Below the appearance of diamond cracks in different polymers was studied. With this aim a set of sieves separating rubber particles of different size was used. For HDPE, if particles were larger than 100-200 $\mu \mathrm{m}$ in size, their fracture initiated formation of diamond cracks, and the composite failed as a macroscopically quasibrittle material. In contrast, if the size of particles was less than $100 \mu \mathrm{m}$, pores were elliptical, the neck propagated along the sample and material did not fail during neck formation. Thus, the particles size 100-200 $\mu \mathrm{m}$ is critical for the HDPE. Smaller particles initiate appearance of elliptical pores. 


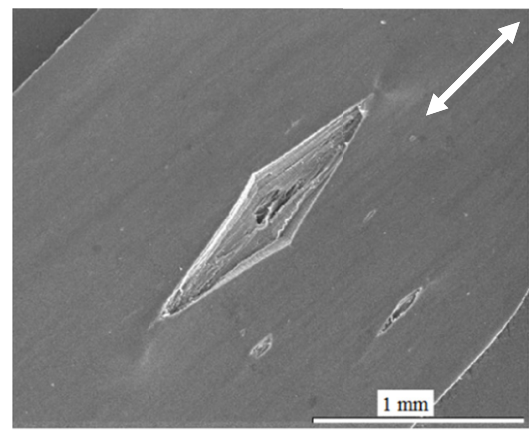

(a)

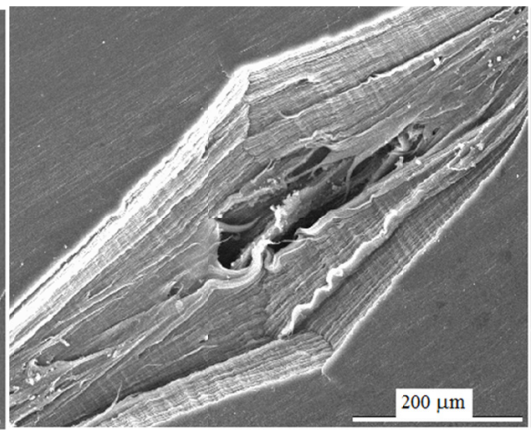

(b)

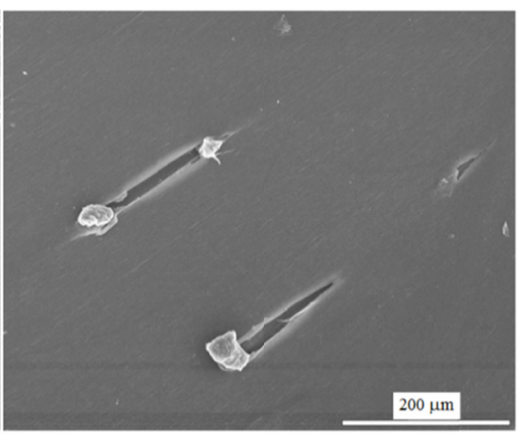

(c)

Figure 3. The diamond crack (a), (b) and elliptical pores (c) in HDPE filled by 17 vol.\% of grinded rubber particles. The arrow shows the tension direction

\subsection{Filled LDPE}

Figure $4 \mathrm{a}$ illustrates failure of LDPE-15803 filled by sieved rubber particles. The large particle, $650-700 \mu \mathrm{m}$ in size, debonds from the matrix under tension and the small elliptical pore is formed (Figure 4a1). Further elongation leads to growth of the pore (Figure 4a2), and it gradually transforms into diamond crack (Figure 4a3). The growth of the diamond crack caused the failure of the sample. Figure $4 \mathrm{~b}$ shows the optical micrograph of the LDPE filled with smaller sieved rubber particles, less than $400 \mu \mathrm{m}$ in size. The sample was not fractured. In the neck, particles are elongated and partially debonded from the matrix. Some particles are fractured. The diamond cracks are not observed, and the neck steadily propagated along the sample. The critical size of particles for the LDPE 15803 is equal to $600-700 \mu \mathrm{m}$.

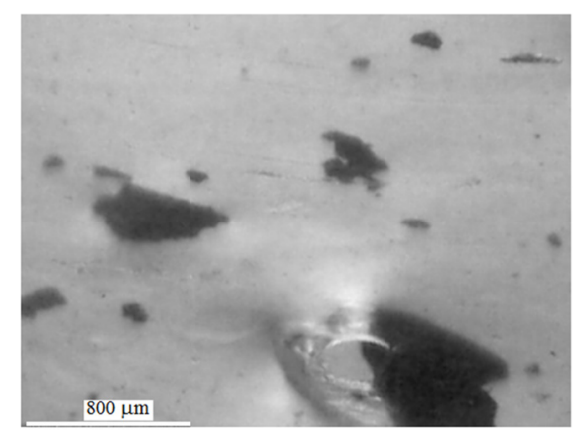

(a1)

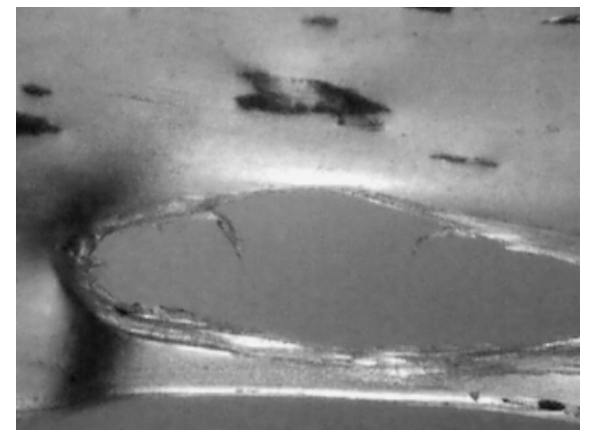

(a3)

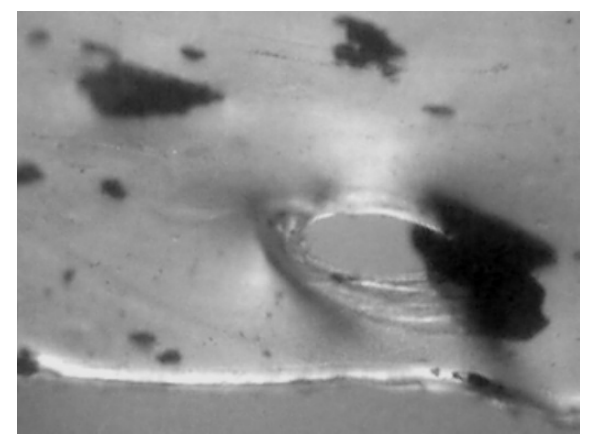

(a2)

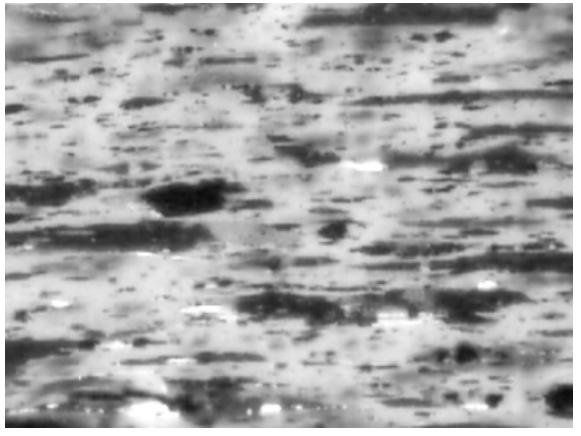

(b)

Figure 4. (a) - Optical photographs of the diamond crack appearance in the sample of LDPE 15803 containing the large rubber particle, $700 \mu \mathrm{m}$ in size; (b) - LDPE filled by sieved rubber particles, less than $400 \mu \mathrm{m}$ in size, at tensile strain of $350 \%$ 


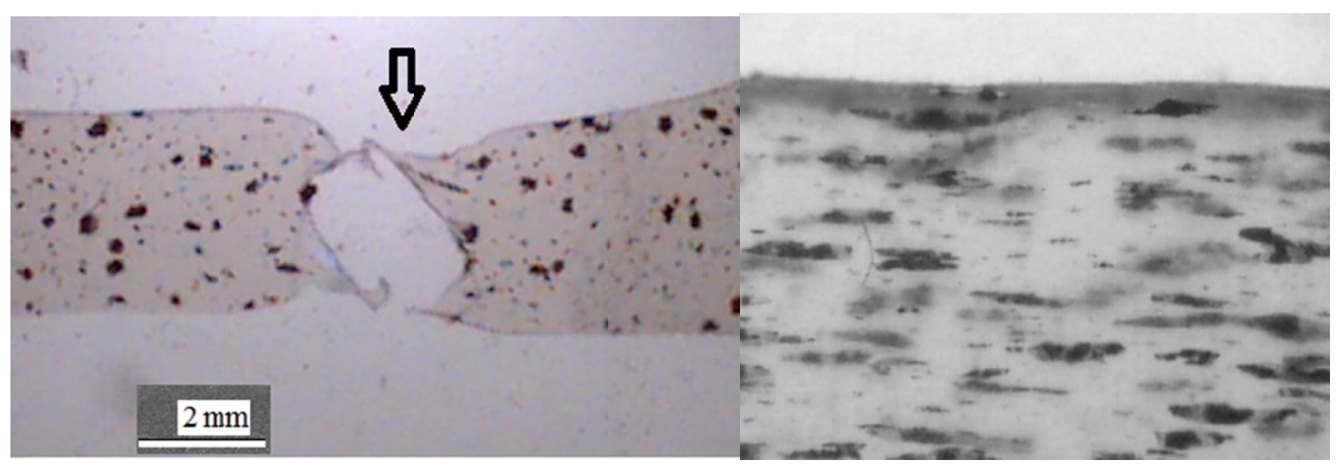

(a)

(b)

Figure 5. Optical photographs of the fractured sample of LDPE 16803 filled by rubber particles with the size of $300-400 \mu \mathrm{m}$ (a); (b) - the surface of the neck of the polymer filled by the particles with size of 100-200 $\mu \mathrm{m}$. The direction of tensile drawing is horizontal

Figure 5a shows a surface of fractured LDPE-16803 sample filled with rubber particles. A diamond crack is formed by the debonded particle, $\sim 350 \mu \mathrm{m}$ in size. The diamond crack grew so fast that the process of its growth could not be record. If the size of particles was less than 100-200 $\mu \mathrm{m}$ in the neck appeared elliptical pores (Figure 5b). The neck propagated through the sample, and the composite was ductile. The critical size of particles for LDPE- 16803 is $300-400 \mu \mathrm{m}$.

\subsection{Filled PP}

Figure 6 illustrates necking of PP filled with rubber particles, 100 to $200 \mu \mathrm{m}$ in size. The rubber particles brake and several elliptical pores appear. The arrow in Figure 6 a shows the necking region. The pores in the forming neck are elongated and gradually transform into the diamond cracks (b). Finally, the diamond crack grew in size (c) and the sample failed. In contrast, in the PP filled with smaller rubber particles, 50 to $100 \mu \mathrm{m}$ in size, pores were elliptical in shape. The diamond cracks did not appear, and the neck propagated along the entire sample without fracture. The diamond cracks appeared if particles size was higher than 100-200 $\mu \mathrm{m}$. If the size of particle was less than $100 \mu \mathrm{m}$, pores were elliptical, and the neck propagated along the sample without fracture. The critical size of particles for PP is $\approx 100 \mu \mathrm{m}$.

\section{Neck formation}

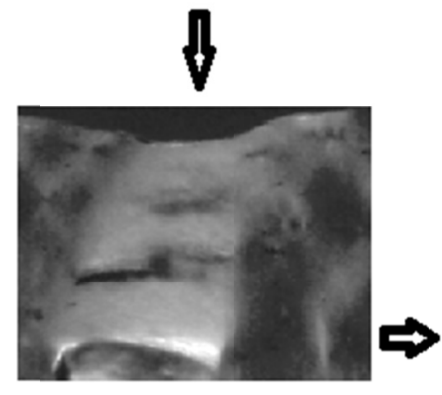

(a)

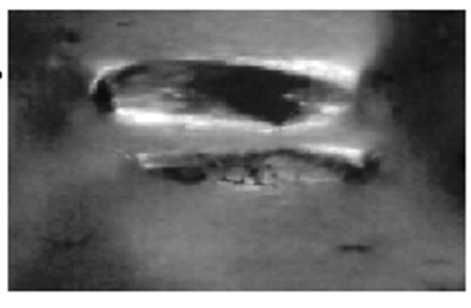

(b)

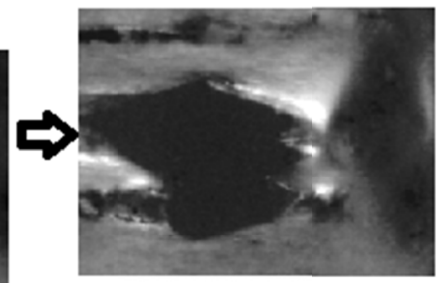

(c)

Figure 6. Optical photographs showing fracture of PP filled by rubber particles with the size of 100-200 $\mu \mathrm{m}$. The arrow on Figure 6a shows the forming neck

Behavior of all studied filled polymers was similar. If the particles size was less than some critical value, in tension they broke or debonded from the matrix, and elliptical pores were formed. The neck propagates along the 
sample and the composite was ductile. In contrast, if the size of particles exceeded the critical value, the diamond cracks appeared, and the composite behaved as a quasibrittle material. The critical size of particles is different for different polymers.

\subsection{Propagation of Crack in Notched Polymers}

Propagation of diamond cracks is similar to growth of a notch under tensile load. Figure 7 illustrates propagation of the crack in HDPE. At comparatively low tensile strains, the crack tip is round (Figure 7a). Elongation leads to gradual crack tip opening, and the crack does not grow. However, at some strain the shape of the crack tip changes, and it transforms into a wedge with the angle of $155^{\circ}$. As a result, the crack propagates through the sample. Schematic of the crack tip zone is presented in Figure 7c.

\subsection{Theoretical Analysis}

The wedge of the growing crack tip resembles a half of a diamond crack. Particularly, the angles of a diamond crack and a notch tip wedge practically coincide. According to linear fracture mechanics, the crack growth starts when the crack tip opening reaches a critical value $\delta=\delta_{c}$ (Leonov \& Panasiuk, 1959; Morozov \& Parton, 1985). When the crack tip opening reaches $\delta_{c}$, a round crack tip transforms into a wedge (Figure 7b). Assuming that the elliptical pore transforms into the diamond crack when the pore elongation reaches the critical crack tip opening $\delta_{c}$, the criterion of the appearance of a diamond crack (onset of fracture) is $\delta=\delta_{c}$.

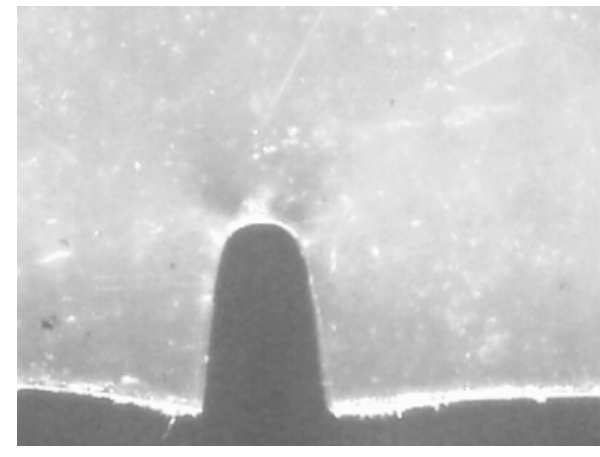

(a)

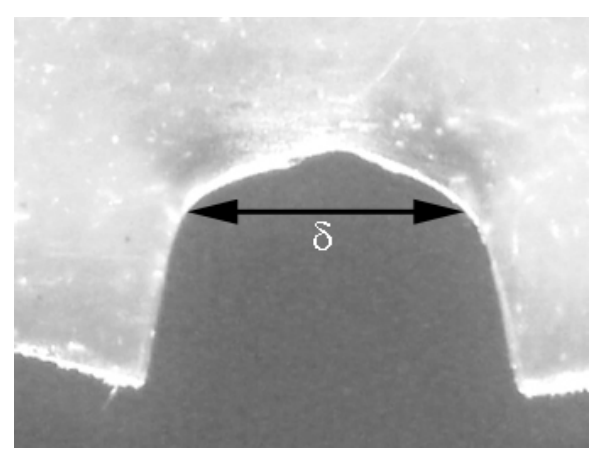

(b)
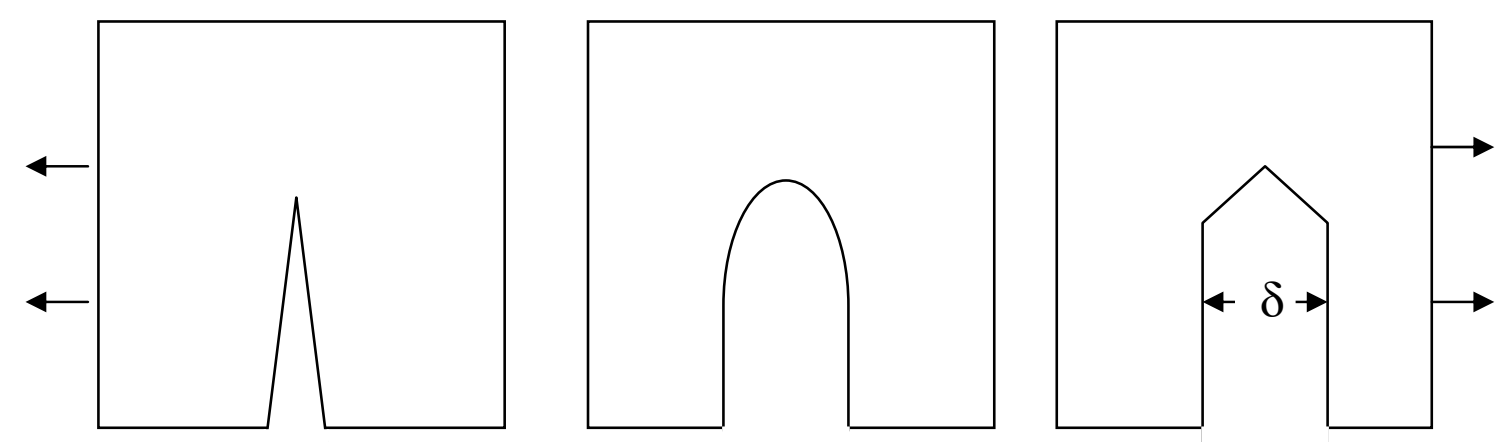

(c)

Figure 7. Propagation of crack in HDPE. (a) rounded crack tip; (b) wedge-shaped crack tip; (c) schematic drawing of a crack growth. Arrows show the direction of tensile drawing

Considering a spherical particle with a diameter $D$, debonded from the matrix, and assuming that tensile strain is uniform, the local strain of the pore is equal to macroscopic strain of the sample. The elongation of the pore is equal to a difference of its current length, $\lambda D$, and the initial diameter, $D$ :

$$
\delta=(\lambda-1) D
$$

where $\lambda=L / L_{0}, L$ and $L_{0}$ are the current and the initial size of a sample. 
An elliptical pore transforms into a diamond crack when the pore elongation (opening) $\delta$ reaches its critical value $\delta_{c}$, and the equality $\delta=\delta_{c}$ is the criterion for appearance of diamond crack. The diamond cracks appear at the draw ratio:

$$
\lambda_{c}=\delta_{c} / D+1
$$

Equation (2) determines the extension ratio at which elliptical pore is transformed into growing diamond crack. If $\lambda_{c}$ is lower than the natural draw ratio of the polymer matrix in neck $\lambda_{d}$, the diamond cracks appear in the forming neck, and composite is quasibrittle. In contrast, if $\lambda_{c}>\lambda_{d}$, diamond cracks appear after propagation of the neck along the sample, and the composite is ductile material. The criterion of the composite embrittlement is $\lambda_{c}=\lambda_{d}$. The criterion $\lambda_{c}=\lambda_{d}$ is fulfilled at the critical dimension of particles $D_{c}$ given by:

$$
D_{c}=\delta_{c} /\left(\lambda_{d}-1\right)
$$

If $D<D_{c}$, diamond cracks appear after propagation of the neck along the sample, and the composite is ductile material. If $D>D_{c}$, diamond cracks appear during neck formation, and composite is quasibrittle.

Experimental values of the draw ratio in neck $\lambda_{d}$, the critical crack tip opening $\delta_{c}$, and the critical size of particles $D_{c}$ are given in Table 1. In the last column of Table 1 values of $D_{c}$ calculated with Equation (3) are presented. The experimental and theoretical $D_{c}$ values agree both for cross-linked rubber particles and rigid $\mathrm{Al}(\mathrm{OH})_{3}$ particles. Figure 8 shows a correlation between the experimental values of the critical particle size, $D_{c}$, and its theoretical value, $\delta_{c} /\left(\lambda_{d}-1\right)$. The correlation is described by a straight line with the slope equal to 1 . Hence, the transformation of an elliptical pore to a diamond crack does occur when the elongation of a pore reaches the critical crack tip opening of the matrix, $\delta_{c}$.

Table 1. The critical crack tip opening, $\delta_{c}$, and the critical size of particles, $D_{c}$, for five polymers

\begin{tabular}{ccccc}
\hline Polymer & $\begin{array}{c}\text { Draw ratio } \\
\text { in neck } \lambda_{d}\end{array}$ & $\begin{array}{c}\text { Critical crack tip } \\
\text { opening } \delta_{c}(\mu \mathrm{m})\end{array}$ & $\begin{array}{c}\text { Experimental critical } \\
\text { particle size } D_{c}(\mu \mathrm{m})\end{array}$ & $\begin{array}{c}D_{c} \text { calculated with } \\
\text { Equation 3 }(\mu \mathrm{m})\end{array}$ \\
\hline LDPE 15803 & 3.3 & 1400 & $600-700$ & 610 \\
LDPE 16803 & 3.4 & 1050 & $300-400$ & 420 \\
PP & 4 & 560 & $100-200$ & 190 \\
HDPE & 4.7 & 680 & $100-200$ & 180 \\
PP* & 5.0 & 140 & 25 & 35
\end{tabular}

*PP with molecular weight 630000 filled with $\mathrm{Al}(\mathrm{OH})_{3}$ particles. Data are taken from the paper of Topolkaraev et al. (1988).

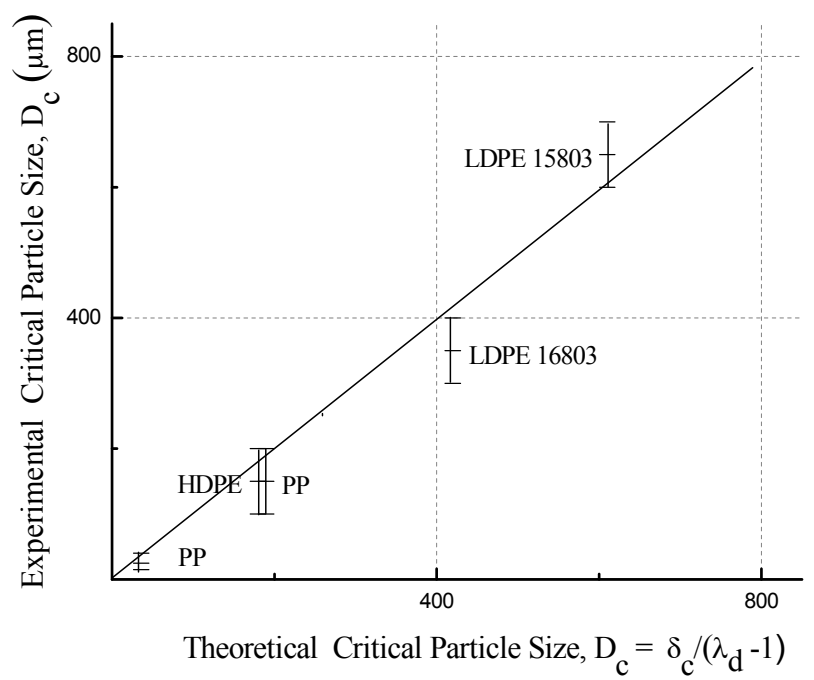

Figure 8. Correlation between the theoretical and experimental values of the critical size of particles 
The critical size of filler particles is determined by the critical crack tip opening $\delta_{c}$ of the matrix which characterizes resistance to crack growth. In addition to $\delta_{c}$, the resistance to crack growth may be characterized by an equivalent characteristic - fracture toughness, $G_{I c}$. Taking into account the relationship between the fracture toughness and the critical crack tip opening, $G_{I c} \approx \sigma_{d} \delta_{c}$ (McClintock, 1971), where $\sigma_{d}$ is the draw stress of the polymer, Equation (3) may be rewritten:

$$
D_{c}=\frac{G_{I c}}{\sigma_{d}\left(\lambda_{d}-1\right)}
$$

The critical particle size is determined by the polymer fracture toughness $G_{I c}$, the draw stress $\sigma_{d}$, and the natural draw ratio in neck $\lambda_{d}$. For thermoplastic polymers quite typical are values $G_{I c}=2-3 \mathrm{~kJ} / \mathrm{m}^{2}, \sigma_{d}=30 \mathrm{MPa}, \lambda_{d}=4$, and the typical critical particle size is estimated as $D_{c}=20-30 \mu \mathrm{m}$.

\section{Discussion}

Large particles are defects initiating fracture of filled polymer. However, the effect of particles dramatically depends on whether the polymer yields by necking or uniformly without necking. Figure 9 compares schematically the effect of particle size on the fracture strain of polymers yielding uniformly (9a) and by necking (9b). The curve 1 on Figure 9a shows the strain, $\varepsilon=\lambda_{c}-1$, of appearance of diamond cracks and the curve 2 the fracture strain of the unfilled polymer. The fracture strain of the composite is equal to the lower of two values determined by curves 1 and 2 . It is shown by the solid line. If particles are small, the fracture strain of the composite is equal to that of the unfilled matrix. If particles are large enough and the curve 1 is under the line 2 , the fracture strain decreases with the particle size. Nevertheless, the composite remains ductile.

If the matrix is necking (Figure 9b), the fracture strain of the composite abruptly drops when the particle size reaches the critical value $D_{c}$. In this case the fracture strain is reached in the forming neck, while outside of the neck the material is in a state of low stretch, and macroscopically material is brittle. The size of filler particles should not exceed the critical value $D_{c}$. If the particle size is higher than $D_{c}$, fracture is caused by diamond crack quickly growing through the necking zone. In contrast, small particles lead to formation of elliptical pores. It is worth mentioning that aggregates of the nanoparticles (Khare \& Burris, 2010) may be similar to a large particle.

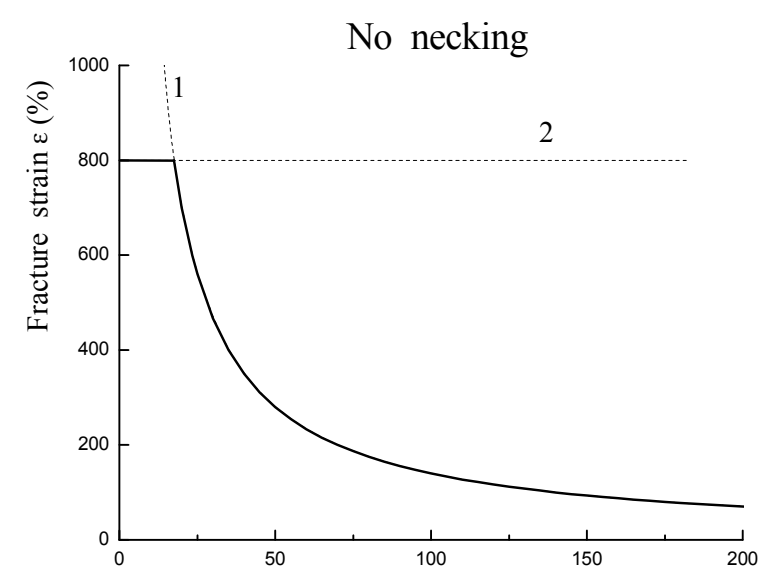

(a) Diameter of particles, $\mathrm{D}(\mu \mathrm{m})$

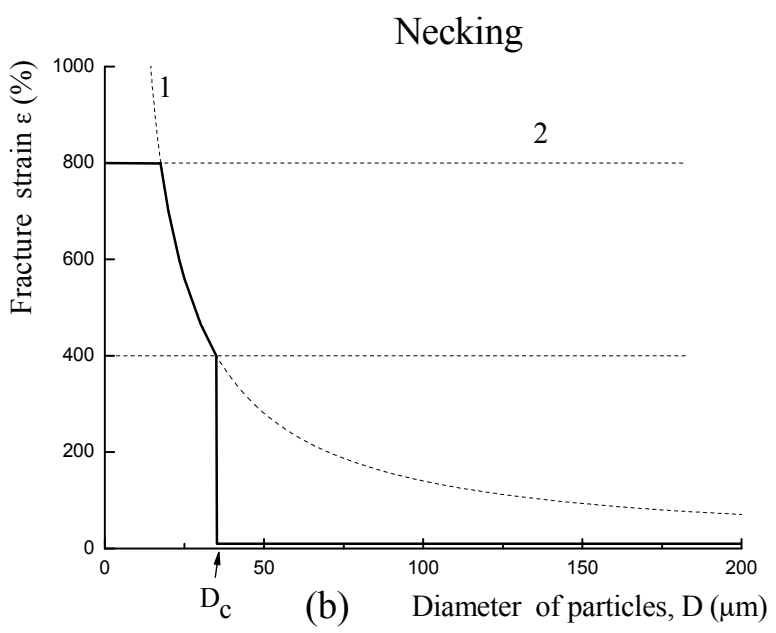

(b) Diameter of particles, $\mathrm{D}(\mu \mathrm{m})$

Figure 9. The fracture strain of filled polymer plotted against the particle diameter $D$ for matrix yielding uniformly (a) and by necking (b). Curve 1 was calculated with equation (2) for $\delta_{c}=140 \mathrm{~m}$ and $\lambda_{d}=5$

An elliptical pore transforms into diamond crack when the pore opening reaches the critical crack tip opening of the unfilled matrix. The criterion of transformation of an elliptical pore into a diamond crack (onset of failure) coincides with the criterion of the onset of notch propagation.

Tensile strength, Young's modulus and toughness of filled polymer composite depend on the size, shape, size distribution, the volume fraction of particles, adhesion of the matrix and the particles. However, the key point determining ductile or brittle behavior of filled polymer is whether the polymer matrix yields uniformly or with necking. If the neck does not appear under tension as in SHMWPE filled by rigid aluminum particles, material 
remains ductile up to very high filler content (Bazhenov, Grinev, Kudinova, \& Novokshonova, 2010). Rubber-like polymers filled with nanosize particles are also ductile materials (Lee, Kontopoulou, \& Park, 2010).

\section{Conclusions}

1) Large filler particles initiate appearance of growing diamond cracks. In contrast, small particles lead to formation of elliptical pores. In the intermediate case pores initially are elliptical, which gradually transform into diamond cracks.

2) The diamond pore is formed when the elongation of an elliptical pore reaches the critical crack tip opening of the polymer matrix.

3) The critical size of particles initiating appearance of diamond pores is determined by the fracture toughness or critical crack tip opening of the matrix.

4) Quasibrittle behavior is typical to filled composites with matrices yielding by necking. In contrast, matrices yielding uniformly without necking usually are not brittle.

\section{References}

Adegbite, S. (2013). Particle characterisation and grinding behaviour of gamma-alumina slurries prepared in a stirred media Mill. Journal of Materials Science Research, 2(1), 135-147. http://dx.doi.org/10.5539/jmsr.v2n1p135

Bailly, M., \& Kontopoulou, M. (2009). Preparation and characterization of thermoplastic olefin/nanosilica composites using a silane-grafted polypropylene matrix. Polymer, 50, 2472-2480. http://dx.doi.org/10.1016/j.polymer.2009.03.034

Bazhenov, S., Li, J. X., Hiltner, A., \& Baer, E. (1994). Ductility of filled polymers. Journal of Applied Polymer Science, 52(2), 243-254. http://dx.doi.org/10.1002/app.1994.070520211

Bazhenov, S. (1997). Stable Crack Growth in Ductile Polymers. Journal of Materials Science, 32(3), 797-802. http://dx.doi.org/10.1023/A:1018572726615

Bazhenov, S. L. (1998). Fillers: Their effect on the failure modes of plastics. Plastics Additives (pp. 252-259). http://dx.doi.org/10.1007/978-94-011-5862-6_28

Bazhenov, S. L., Goncharuk, G. P., Knunyats, M. I., Avinkin, V. S., \& Serenko, O. S. (2002). The effect of rubber particle concentration on the fracture mechanism of a filled HDPE. Polymer Science, Ser. A, 44(4), 393-401.

Bazhenov, S. L., Grinev, V. G., Kudinova, O. I., \& Novokshonova, L. A. (2010). On the fracture of composites based on ultrahigh-molecular-weight polyethylene and fine aluminum particles. Polymer Science, Ser. A, 52(5), 549-556. http://dx.doi.org/10.1134/S0965545X1005010X

Bucknall, C. B., Cote, F. F. P., \& Partridge, I. K. (1986). Rubber toughening of plastics. Journal of Materials Science, 21(1), 301-306. http://dx.doi.org/10.1007/BF01144736

Chao, H., \& Riggleman, R. A. (2013). Effect of particle size and grafting density on the mechanical properties of polymer nanocomposites. Polymer, 54, 5222-5229.

Griffith, A. A. (1921). The phenomena of rupture and flow in solids. Philos. Trans. Roy. Soc. Lond., Ser. A, 221, 163-198.

Khare, H. S., \& Burris, D. L. (2010). A quantitative method for measuring nanocomposite dispersion. Polymer, 51, 719-729. http://dx.doi.org/10.1016/j.polymer.2009.12.031

Knunyants, M. I., Chepel, L. M., Kryuchkov, A. N., Zelenetskii, A. N., Prut, E. V., \& Enikolopyan, N. S. (1988). The effect of thechnology parameters on the properties of polyethylene filled by crosslinked rubber. Mechanics of Composite Materials, 23(5), 927-932.

Lauke, B. (2009). Effect of particle size distribution on fracture toughness of polymers. Proceedings of 11th Pan-American Congress of Applied Mechanics, Foz do Iguaçu, PR, Brazil.

Lee, S. H., Kontopoulou, M., \& Park, C. B. (2010). Effect of nanosilica on the co-continuous morphology of polypropylene/polyolefin elastomer blends. Polymer, 51, 1147-1155. http://dx.doi.org/10.1016/j.polymer.2010.01.018

Leonov, M. Ya., \& Panasiuk, V. V. (1959). Propagation of fine cracks in solids. Prikladnaya Mekhanica, 5(4), 391-401. 
Li, J. X., Silverstein, M., Hiltner, A., \& Baer, E. (1994). The ductile to quasibrittle transition of particulate filled thermoplastic polyester. Journal of Applied Polymer Science, 52(2), 255-267. http://dx.doi.org/10.1002/app.1994.070520212

McClintock, F. A. (1971). In H. Liebowitz (Ed.), Plasticity aspects of fracture, in: Fracture (Vol. 3, pp. 47-225). New York: Academic Press.

Morozov, E. M., \& Parton, V. Z. (1985). Elastic-plastic fracture mechanics. Moscow: Mir Publishers.

Orowan, E. O. (1949). Fracture and the strength of solids. Rep. Prog. Phys., 12, 185-232. http://dx.doi.org/10.1088/0034-4885/12/1/309

Rajalingam, P., Sharpe, J., \& Baker, W. E. (1993). Ground Rubber Tire/Thermoplastic Composites: Effect of Different Ground Rubber Tires. Rubber Chemical Technology, 66(4), 664-672. http://dx.doi.org/10.5254/1.3538337

Ramsteiner, F., \& Theysohn, R. (1984). On the tensile behavior of filled composites. Composites, 15(2), 121-128.

Tao, Z. J., Ping, S. D., Mei, Z., \& Cheng, Z. -P. (2013). Microstructure deformation and fracture Mechanism of highly filled polymer composites under large tensile deformation. Journal of Physics: Conference Series, 419, 012014. http://dx.doi.org/10.1088/1742-6596/419/1/012014

Topolkaraev, V. A., Tovmasyan, Yu. M., Dubnikova, I. L., Petrosyan, A. I., Meshkova, I. N., Berlin, Al. Al., ... Shilov, V. V. (1988). Effect of the size of inclusions on structural organization and deformation behaviour of high-density filled polyethylene with different molecular mass. Mechanics of Composite Materials, 23(4), 419-425. http://dx.doi.org/10.1007/BF00611108

Wu, O., \& Mai, Y.-W. (1993). Fracture toughness and fracture mechanisms of PBT/PC/IM blend. Journal of Materials Science, 28(22), 6167-6177. http://dx.doi.org/10.1007/BF00365039

\section{Copyrights}

Copyright for this article is retained by the author(s), with first publication rights granted to the journal.

This is an open-access article distributed under the terms and conditions of the Creative Commons Attribution license (http://creativecommons.org/licenses/by/3.0/). 